\title{
CD161-expressing human T cells
}

\author{
Joannah R. Fergusson ${ }^{1}{ }^{*}$, Vicki M. Fleming ${ }^{2}$ and Paul Klenerman ${ }^{2,3}$ \\ 1 Sir William Dunn School of Pathology, University of Oxford, Oxford, UK \\ 2 Peter Medawar Building for Pathogen Research, University of Oxford, Oxford, UK \\ ${ }^{3}$ Biomedical Research Centre, John Radcliffe Hospital, Oxford, UK
}

Edited by:

Liisa Kaarina Selin, University of Massachusetts Medical School, USA

Reviewed by:

Joshua J. Obar, Montana State University, USA

Kristin Hogquist, University of

Minnesota, USA

\section{${ }^{*}$ Correspondence}

Joannah R. Fergusson, Sir William

Dunn School of Pathology, South

Parks Road, Oxford OX1 3RE, UK.

e-mail: joannah.fergusson@

path.ox.ac.uk
Expression of the Natural Killer cell receptor CD161 has recently been identified on a subset of T cells, including both CD4+T helper and CD8+T cells. Expression of this molecule within the adult circulation is restricted to those T cells with a memory phenotype. However, the distinct properties of these T cell populations is yet to be fully determined, although expression of CD161 has been related to the secretion of interleukin-17, and therefore to a type 17 phenotype. Recent studies have aimed to determine both the origin of these cells and the significance of CD161 expression as either a marker of specific cell types or as an effector and regulator of lymphocyte function, and hence to characterize the role of these CD161+ cells within a variety of human diseases in which they have been implicated.

Keywords: CD161, interleukin-17,T cells, T helper 17 cells, NK cells, NK-T cells, NKRP1

\section{INTRODUCTION}

The study of immunology is largely based on the division of leukocytes into families, lineages, and subsets; from division between innate and adaptive immunity, to categorization based on surface molecule expression and cytokine secretion. Many of those surface molecules involved in identification of subtype also reflect effector function. However, as further cells are identified these divisions become less distinct, with some cells demonstrating features from one or more of the previously defined subsets. As these molecules are often involved in effector function, common expression of molecules between lineages may suggest overlapping functions.

One set of divisions which are becoming increasingly "blurred" are those between T lymphocytes, Natural Killer (NK) cells, and NK-T cells. These subsets share common expression of specific molecules, including the C-type lectin CD161. This surface molecule was originally identified as the human homolog of the NKRP1 glycoproteins expressed on rodent NK cells, demonstrating 46$47 \%$ homology with its rodent counterparts. Human NKRP1A, or CD161, is composed of a disulfide-linked homodimer of $\sim 40 \mathrm{kDa}$ subunits. It is expressed by the majority of NK cells and approximately $24 \%$ of peripheral $\mathrm{T}$ cells (Lanier et al., 1994), including both $\gamma \delta$ and $\alpha \beta$ TCR-expressing subsets (Maggi et al., 2010) and NK-T cells. As NK-T cells compose less than $1 \%$ of human peripheral blood $\mathrm{T}$ cells (Gumperz et al., 2002), the remaining CD161+ T cells must represent a distinct lineage of $\mathrm{T}$ lymphocytes (Takahashi et al., 2006).

However, the implication of CD161 expression by these T cells remains to be fully determined - is CD161 simply a phenotypic marker; identifying $\mathrm{T}$ cells of a common activation state and/or lineage? Or does this C-type lectin perform some significant effector function itself? This review aims to explore recent advances in the characterization of CD161-expressing $\mathrm{T}$ cells, concentrating particularly on human $\alpha \beta$-TCR T cells, and through this to evaluate the importance of expression to immune function and hence to human disease.

\section{CD161 AS A PHENOTYPIC MARKER OF T CELLS}

CD161 expression is not unique to any predefined T cell subset. Lanier et al. (1994) originally identified expression on both CD4+ and CD8+ T cells, with a higher surface density on the latter. More recently, CD161 expression has also been demonstrated on CD4-CD8- double negative (DN) TCR $\alpha \beta+$ and TCR $\gamma \delta+$ T cells (Maggi et al., 2010). Further analysis has identified two CD161+CD8+ populations (Takahashi et al., 2006; Billerbeck et al., 2010), with intermediate or high CD161 expression levels, and one $\mathrm{CD} 161+\mathrm{CD} 4+\mathrm{T}$ cell population expressing intermediate levels of CD161 only (Takahashi et al., 2006; Kang et al., unpublished observation), as shown in Figure 1. The functional relationship between the two populations of $\mathrm{CD} 161$ positive $\mathrm{CD} 8+\mathrm{T}$ cells, and the significance of a CD161 ${ }^{\text {high }}$ population within CD8+ T cells which is largely absent from the CD4+ population, is yet to be fully defined.

\section{CD161 AS A MARKER IL-17 PRODUCING CELLS}

The identity of these CD161-expressing T subsets remained elusive until CD161 was identified as being significantly upregulated in T helper (Th) 17 clones compared to those of Th1 and Th2 (Cosmi et al., 2008). These CD4+ Th17 cells represent a novel helper cell subset, which secrete both IL-17A and IL-17F and express the master transcription factor retinoic acid-related orphan receptor (ROR) $\gamma \mathrm{t}$ (Ivanov et al., 2006). In peripheral blood, IL-17 secreting $\mathrm{CD} 4+$ cells are contained within the $\mathrm{CD} 161+$ fraction and these cells express ROR $\gamma$ t. Hence, CD161 is considered a hallmark of Th17 cells.

As a result of the correlation between IL-17 secretion and CD161 amongst Th17 cells, Maggi et al. (2010) investigated CD161 expression in other T cells capable of producing IL-17. In addition to Th17 cells, IL-17 secreting CD8+ T cells have also been isolated from the circulation of healthy individuals (Kondo et al., 2009). Interestingly, in all $\mathrm{T}$ cell subsets, including these CD8+ T cells, the ability to secrete IL-17 was virtually restricted 

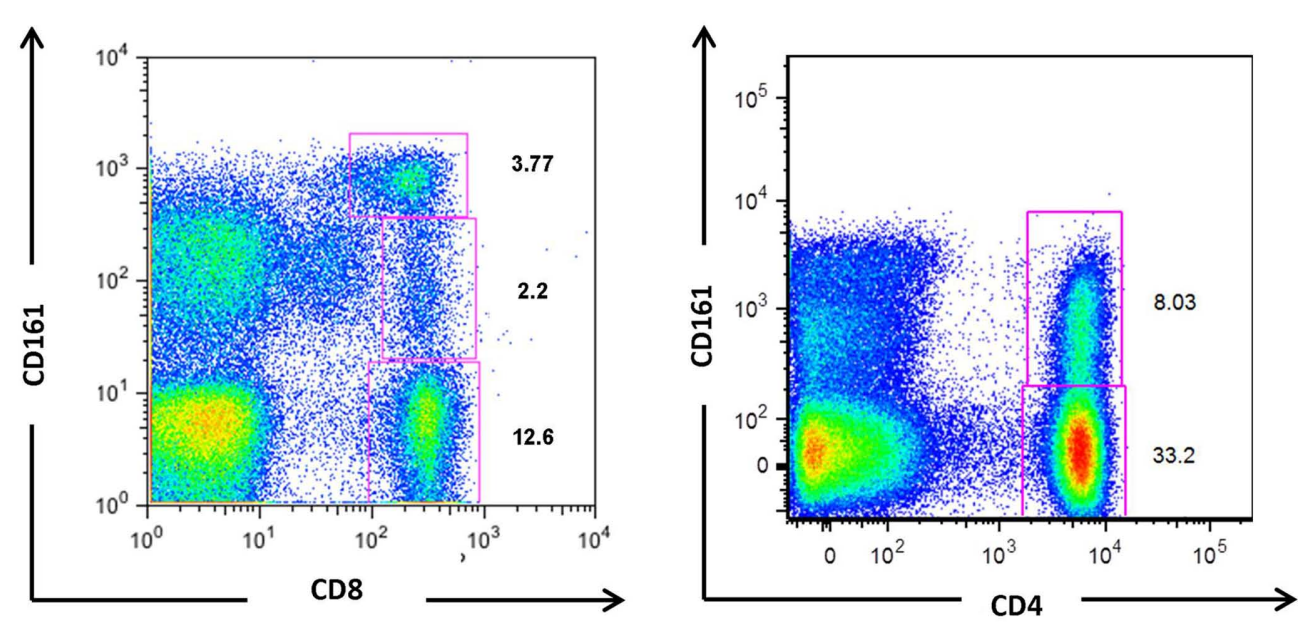

FIGURE 1 | CD161-expressing populations in CD8+ and CD4+ T cells. Flow cytometric analyses of T cells from healthy individuals demonstrate the existence of three populations of CD8+T cells; CD161- ${ }^{-}$CD161 $1^{\text {int }}$, and CD161 ${ }^{\text {high }}$, and two CD4+ T cell populations; CD161- and CD161 int Some donors may display a $C D 161^{\text {high }} \mathrm{CD} 4+$ population, but in the majority CD161 positive CD4+ $\mathrm{T}$ cells comprise a single population with intermediate expression levels.

to those cells expressing CD161. These CD161+ cells express the Th17 transcription factor ROR $\gamma$ t. Furthermore, Maggi et al. (2010) demonstrated that naïve CD161-CD4+ T cells transduced with ROR $\gamma$ t produced IL-17 and upregulated CD161 expression, while inhibition of ROR $\gamma \mathrm{t}$ downregulated both IL-17 and CD161 expression in Th17 clones. Similarly, ROR $\gamma \mathrm{t}$ transduction in differentiating CD8 + T cells induced high levels of IL-17 production when these cells were cultured in the presence of Th17-polarizing cytokines (Huber et al., 2009). Thus, the observed correlation between IL-17 production and CD161 expression may result from dual control of gene expression by the transcription factor ROR $\gamma t$, which may be activated or upregulated under type 17-polarizing conditions.

CD8 + T cells capable of secreting IL-17 have been further characterized by Billerbeck et al. (2010). This study demonstrated IL-17 secretion amongst CD8 $+\mathrm{T}$ cells was restricted to those expressing high levels of CD161. CD161 $1^{\text {high }} \mathrm{CD} 8+$ cells display a phenotype similar to Th17 cells, such as the upregulated expression of ROR $\gamma t$, CCR6, and IL-18R, and as such have been described as Tc17 cells. Although these cells express the CD8 co-receptor, Tc17 cells display reduced cytotoxic potential compared to conventional CD8+ effector $\mathrm{T}$ cells associated with a low expression of granzyme $\mathrm{B}$ and perforin, and reduced cytotoxic degranulation as measured by CD107a upregulation. Tc17 populations independently described in mice also displayed limited cytolytic capability, with only a very small fraction positive for granzyme B (Hamada et al., 2009; Huber et al., 2009).

\section{AREAS OF CONTROVERSY}

However, several opposing theories have recently emerged regarding the identity of CD8 + T cells expressing high levels of CD161, summarized in Table 1. CD161, when co-expressed with IL-18R $\alpha$, has also been suggested as a marker of a prototypical CD8+ population known as memory stem cells (Turtle et al., 2009), which survive cytotoxic chemotherapy through the rapid efflux of cytotoxic drugs. Like those cells described by Billerbeck et al.
(2010), these memory cells expressed low levels of granzyme B and perforin, demonstrated reduced proliferation, and were CD28+ and CD27+. However, Dusseaux et al. (2011) suggest that in healthy adults $\mathrm{CD} 161^{\text {high }} \mathrm{CD} 8+\mathrm{T}$ cells largely represent mucosal associated invariant T (MAIT) cells; an innate-like T cell subset which express the invariant $\mathrm{TCR} \alpha$ chain $\mathrm{V} \alpha 7.2-\mathrm{J} \alpha 33$ and are restricted by MHC-related molecule 1 (MR1; Martin et al., 2009). Approximately $10 \%$ of MAIT cells were found to express IL-17 in response to PMA and ionomycin and these cells expressed ROR $\gamma \mathrm{t}$. MAIT cells have therefore also been suggested to represent Tc17 cells. However, while Tc17 cells can react to viral peptides (Billerbeck et al., 2010), MAIT cells were unable to react to virus-infected APCs (Le Bourhis et al., 2010). Further studies are consequently required to clarify the degree of overlap between these putative cell types. Current analysis of Tc17 cells indicates that although the majority, like MAIT cells, are V $\alpha 7.2+$, these cells do not completely encompass the CD161 ${ }^{\text {high }}$ population (Walker et al., 2010).

\section{CD161 AND MEMORY PHENOTYPE}

Despite this disagreement regarding TCR usage, in all studies CD161 expression is consistently associated with a memory phenotype within the adult circulation, being described in CD4+ (Takahashi et al., 2006; Annunziato et al., 2007; Cosmi et al., 2008; Kleinschek et al., 2009), CD8+ (Takahashi et al., 2006; Maggi et al., 2010), DN TCR $\alpha \beta+$, and TCR $\gamma \delta+$ T cells (Maggi et al., 2010). Whereas approximately half of CD161 ${ }^{\text {int }} \mathrm{CD} 4+\mathrm{T}$ cells display a central memory phenotype, being CD62L + CCR7+, less than $1 \%$ of $\mathrm{CD} 161^{\text {high }} \mathrm{CD} 8+\mathrm{CD} 45 \mathrm{RO}+$ cells expressed this phenotype, and are therefore classed as being effector memory cells (Takahashi et al., 2006). This may suggest that CD161 expression is acquired as a result of immune stimulation, and may itself be a memory marker. However, CD161 negative cells do not alter in CD161 expression with anti-CD2, -CD3 and -CD28 stimulation, and influenza-specific cells did not express CD161 after re-stimulation, even in the presence of cytokines (Northfield et al., 2008), implying that CD161 is not simply a marker of activation. 
Table 1 | Three parallel characterizations of CD161 ${ }^{\text {high }} \mathrm{CD} 8+\mathrm{T}$ cells.

\begin{tabular}{|c|c|c|c|}
\hline & $\begin{array}{l}\text { MAIT cells (Martin et al., 2009; Gold } \\
\text { et al., 2010; Dusseaux et al., 2011) }\end{array}$ & $\begin{array}{l}\text { Tc17 cells (Northfield et al., 2008; } \\
\text { Billerbeck et al., 2010) }\end{array}$ & $\begin{array}{l}\text { CD8 memory stem cells } \\
\text { (Turtle et al., 2009) }\end{array}$ \\
\hline Surface phenotype & V $\alpha 7.2+C D 161^{\text {high }}$ IL-18R $\alpha+$ & CD161 ${ }^{\text {high }}$ IL-18R+ & CD161 high IL-18R $\alpha+$ Rh123-effluxing \\
\hline Cord blood & Present: CD45RA+CD161 high IL-18R $\alpha+$ & Present: CD45RA+CD161 high $C C R 6+$ & Absent \\
\hline IL-17 production & Yes & Yes & Unknown \\
\hline ROR $\gamma \mathrm{t}$ & Expressed & Expressed & Unknown \\
\hline Specificity & Respond to bacterially infected APCs & $\begin{array}{l}\text { Some specificity for HCV demonstrated, but } \\
\text { not for other viruses, e.g., HIV, CMV, and } \\
\text { influenza }\end{array}$ & $\begin{array}{l}\text { Respond to APCs pulsed with viral } \\
\text { peptides }\end{array}$ \\
\hline
\end{tabular}

This table illustrates both the similarities and differences between the main observations concerning the phenotype of CD161 high CD8+ T cells. Billerbeck et al. (2010) characterize these cells as TC17 cells, reflecting their similarity to Th17 cells, while Turtle et al. (2009) identified high expression of CD161 as a marker of CD8+ memory stem cells. A recent study by Dusseaux et al. (2011), however, suggests that both these cell types represent the previously characterized MAIT cell population.

Furthermore, CD161 is expressed both by a subset of T cells in the fetal liver and on a minor population of $\mathrm{CD} 3+$ thymocytes (Lanier et al., 1994; Martin et al., 2009). This indicates, therefore, that expression is induced early in ontogeny. CD161 ${ }^{\text {int }} \mathrm{CD} 4+$ (Cosmi et al., 2008) and CD161 ${ }^{\text {high }} \mathrm{CD} 8+$ (Martin et al., 2009; Billerbeck et al., 2010) T cells have also been isolated from umbilical cord blood (UCB), where they display a naïve phenotype. When cultured in the presence of Th17-polarizing cytokines, development of IL-17 production is restricted to the CD161+CD4+CD45RA+ fraction (Cosmi et al., 2008), implying that Th17 cells originate from a CD161+CD4+ $\mathrm{T}$ cell progenitor. This suggests that those CD161+ cells identified in cord blood represent the precursors of memory CD161+ $\mathrm{T}$ cells found in adults. What induces the maturation of these cells to display a memory phenotype after birth is yet to be defined.

\section{CD161 AS AN EFFECTOR MOLECULE}

It is clear that determining the function of CD161 would greatly aid the functional phenotyping of those cells expressing this Ctype lectin. Crosslinking of CD161 by anti-CD161 antibodies has previously had variable effects on both human NK and T cells. Aldemir et al. (2005), observed that ligation of CD161 was not sufficient to trigger IFN- $\gamma$ production by $\mathrm{T}$ cells, yet did enhance secretion with the simultaneous engagement of CD3. Conversely, Rosen et al. $(2005,2008)$ found that crosslinking of CD161 did not affect cytokine production in CD4+ T cells, but reduced TNF $\alpha$ production by CD8 $+\mathrm{T}$ cells in a proportion of donors tested.

\section{CD161 LIGANDS}

As the only human ortholog of the rodent NK receptor family known as NKRP1, a central aim in determining the function of CD161 is the identification of this receptor's ligand(s). Seven murine NKRP1 genes have thus far been identified, termed Nkrpla-g (with Nkrple thought to be a pseudogene; Plougastel et al., 2001a), heterogeneously expressed by NK cells (Aust et al., 2009). In C57BL/6 mice NKR-P1C carries the NK cell antigenic marker NK1.1 (Glimcher et al., 1977; Koo and Peppard, 1984) and also marks murine NK-T cells (MacDonald, 1995). This NKRP1 receptor may also be expressed during activation of CD8+ T cells (Aust et al., 2009). Unlike classical NK cell receptors, NKRP1 receptors recognize non-MHC ligands of the C-type lectin related (Clr) family, encoded by genes interspersed within the Nkrp1 genes themselves (Plougastel et al., 2001b; lizuka et al., 2003). Yet, like other NK cell receptors, $N k r p 1$ gene products can be classified as either activating or inhibitory. NKRP1A, $\mathrm{C}$ and $\mathrm{F}$ contain charged residues within their transmembrane domains, and are therefore considered to be activating receptors, inducing NK cytolytic activity, while NKRP1B and NKRP1D lack charged transmembrane residues and deliver inhibitory signals when crosslinked (Aust et al., 2009). NKRP1B and D appear to be closely related inhibitory molecules, expressed in BALB/c and C57BL/6 mice, respectively, with the Nkrp1d gene of C57BL/6 mice suggested to represent a divergent allele of the Nkrplb gene of other strains (Carlyle et al., 2006). Both NKRP1B and D bind the Clr-b protein osteoclast inhibitory lectin (Ocil; Carlyle et al., 2004). The human ortholog of this ligand, also known as lectin-like transcript 1 (LLT1), was simultaneously identified by two groups as a ligand for CD161 in humans (Aldemir et al., 2005; Rosen et al., 2005). This interaction, conserved between mouse and man, may suggest that NKRP1B and D represent the closest relations to human CD161. The suggested ligands for murine NKRP1 receptors and human CD161 are shown in Figure 2.

In humans, LLT1 is thought to be expressed by both activated APCs (Aldemir et al., 2005; Rosen et al., 2008) and lymphocytes (Aldemir et al., 2005). Despite transcripts and proteins of CD161 being identical between NK and T cells, ligation by LLT1 appears to induce opposing effects in these subsets, inhibiting or enhancing IFN $\gamma$ production, respectively. A subsequent $\mathrm{CD} 161$ ligand, related to LLT1, has also been recently identified, termed proliferationinduced lymphocyte-associated receptor (PILAR; Huarte et al., 2008). As its name implies, PILAR is expressed on lymphocytes and expression is upregulated in T cells upon TCR stimulation. In the absence of $\mathrm{CD} 28$ costimulation, PILAR increases the proliferation of naïve T cells, suggesting that CD161 acts as a costimulatory receptor, enhancing proliferation through interaction with PILAR. Lately, however, the interaction between PILAR and CD161 has 


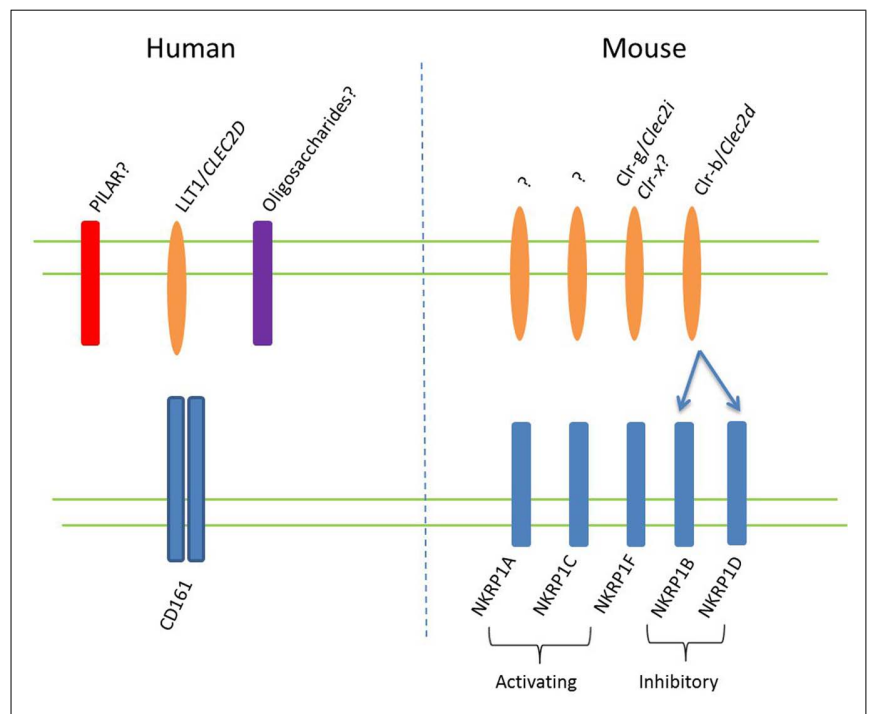

FIGURE 2 | NKRP1 ligands in mouse and man. Putative ligands for CD161, expressed on human T lymphocytes, are shown on the left side of the figure. The CD161 ortholog in mice exists as a family of genes, known as NKRP1 receptors, which are thought to consist of at least three activating and two inhibitory receptors, as shown on the right. The ligands for these receptors are $\mathrm{Cl}$ proteins, with the two known ligands depicted. A recent study suggested that NKRP1F may also recognize Clr-x (Aust et al., 2009).

been disputed, and it has been suggested that the PILAR gene encodes a ligand (termed keratinocyte-associated C-type lectin, $\mathrm{KACL}$ ) which interacts with a distinct receptor, a further C-type lectin named NKp65 (Spreu et al., 2010).

\section{CD161 AND TISSUE HOMING}

CD161 has also been proposed to play a role in transendothelial migration. CD161+ cells migrated across endothelial cell monolayers to a greater extent than CD161-CD4+ lymphocytes (Poggi et al., 1997), and this was reduced by incubation with anti-CD161 monoclonal antibody. This may occur through binding of CD161 to acidic oligosaccharides on the endothelial cell surface, as has been shown in NK cells (Bezouska et al., 1994). Interestingly, migration occurred without chemotactic stimuli, which may be indicative of a preference of these cells to home to specific tissues. Indeed, both CD4+ and CD8+ CD161+ T cells make up more than half of T cells in the healthy human intestine (O'Keeffe et al., 2004) and CD161-expressing CD8+ T cells appear to home to the liver (Ishihara et al., 1999).

\section{CD161 EXPRESSION AND DISEASE CD161+ T CELLS AND INFECTION}

These cells are also selectively recruited during inflammation, with CD4+ (Kang et al., unpublished observation) and CD8+ CD161+ $\mathrm{T}$ cells enriched in the liver in response to both hepatic infection and non-alcoholic steatohepatitis (Billerbeck et al., 2010). CD8 + T cells specific for HCV and hepatitis B (HBV), but not HIV, cytomegalovirus (CMV), or influenza, express significant levels of CD161 (Northfield et al., 2008) and these T cells display responses against HCV-derived peptides (Billerbeck et al., 2010). $\mathrm{CD} 161^{\text {int }} \mathrm{CD} 4+\mathrm{T}$ cells are also markedly enriched in the liver of patients with HCV (Kang et al., unpublished observation) and HCV-specific Th17 cells have been described (Rowan et al., 2008). Expression of CD161, particularly on CD8+ T cells, may therefore differentiate responses within specific organs such as the liver. Yet the role of these cells in either disease control or immune-mediated damage is largely unknown. Recently, Wang et al., correlated levels of IL-17 with degree of fibrosis in HBV infection, with intrahepatic IL-17 localized to fibrotic regions (Wang et al., 2011). Conversely, secretion of IL-22 by these cells may in fact be hepatoprotective (Zenewicz et al., 2007; Kang et al., unpublished observation).

However, these cells are not limited to liver-specific responses. Tc17 populations within mice protect against lethal influenza infection (Hamada et al., 2009), an effect shown to be due, at least partially, to their secretion of IL-17. CD161+ MAIT cells, on the other hand, respond to bacterially infected cells, including both APCs (Le Bourhis et al., 2010) and Mycobacterium tuberculosis-infected lung epithelial cells (Gold et al., 2010), suggesting a role in detection and control of bacterial infections. MAIT cells are thought to be unresponsive to virus-induced or virusderived ligands (Le Bourhis et al., 2010). Resolution of CD161expressing CD8+ T cell specificity, in addition to aiding classification, would also assist the identification of their role within human disease.

\section{CD161+ T CELLS IN AUTOIMMUNE DISEASE}

In contrast to the situation with host defense, much research has concentrated on the role of $\mathrm{CD} 161^{\text {int }} \mathrm{CD} 4+\mathrm{T}$ cells in autoimmune disease, which was previously considered to be Th1-driven (Cua et al., 2003). IL-17 knockout mice exhibit delayed onset, reduced severity, and early recovery of experimental autoimmune encephalomyelitis (EAE), the murine model of multiple sclerosis (MS). In humans, IL-17 levels are increased in patients with MS (Lock et al., 2002) and IL-17+ T cells have been identified within MS brain lesions (Tzartos et al., 2008). Patients with MS also display a significantly higher percentage of peripheral blood CD161 ${ }^{\text {high }} \mathrm{CD} 8+\mathrm{T}$ cells than healthy individuals (Annibali et al., 2011). More specifically, polymorphisms in CD161 have recently been implicated in MS, suggesting a role for CD161 itself in autoimmune pathogenesis (Hafler et al., 2007).

CD161-expressing T cells have also been implicated in other autoimmune diseases. High proportions of CD161 int $\mathrm{CD} 4+\mathrm{T}$ cells were found in inflammatory infiltrates of patients with psoriasis (Cosmi et al., 2008) and Crohn's disease (CD; Kleinschek et al., 2009). Indeed, CD161 ${ }^{\text {int }}$ CD4+ T cells demonstrated a 20fold increase in gut samples from patients with CD compared to healthy controls and those isolated from the blood produced significantly more IL-17 on stimulation with PMA and ionomycin. Tc17 cells are also significantly enriched in inflammatory infiltrates from donors with psoriatic and rheumatoid arthritis (RA; Billerbeck et al., 2010). However, the significance of CD161 expression by both Th17 and Tc17 within the disease process has yet to be determined.

\section{CONCLUSION AND FUTURE WORK}

CD161 expression is evident within all T cell subsets, and is associated with cells expressing a memory phenotype in the adult circulation. However, CD161 does not simply represent a marker 
of activation, memory, or exhaustion. Neither stimulation nor restimulation induced expression in CD161 - cells, and CD161+ cells express only low levels of the exhaustion marker PD-1 (Northfield et al., 2008; Billerbeck et al., 2010). Furthermore, CD161 expression has been identified in naïve cells within UCB (Cosmi et al., 2008; Billerbeck et al., 2010), with CD45RA+CD161+CD4+ $\mathrm{T}$ cells expressing high levels of mRNA for ROR $\gamma \mathrm{t}$, IL-23R, and CCR6. CCR6 is also expressed on $\mathrm{CD} 161^{\text {high }} \mathrm{CD} 8+\mathrm{T}$ cells isolated from cord blood (Billerbeck et al., 2010). This suggests that these CD161 positive cells, while apparently naïve, represent a population precommitted to a distinct pathway of differentiation.

During ontogeny $\mathrm{T}$ cells develop within the thymus, where lineage commitments such as CD4 vs. CD8 co-receptor expression are made. These fate decisions influence the phenotype of these cells upon their release into the periphery. Interestingly, single positive thymocytes from the post-natal thymus which express CD161 have also been identified (Lanier et al., 1994; Cosmi et al., 2008; Martin et al., 2009). This, together with early expression of ROR $\gamma \mathrm{t}$ and characteristic cytokine receptors in UCB CD161+ lymphocytes, suggests that expression of CD161 may indicate an early lineage commitment made by cells during development. Indeed, this decision may even be made prior to division into CD4 or CD8 subtype, with the possible pathways by which CD161+ cells develop illustrated in Figure 3. It appears that these CD161+ thymocytes represent the precursors of those memory Th17 and Tc17 cells identified within the adult circulation. Expression of CD161 early in ontogeny could also explain the identification by Turtle

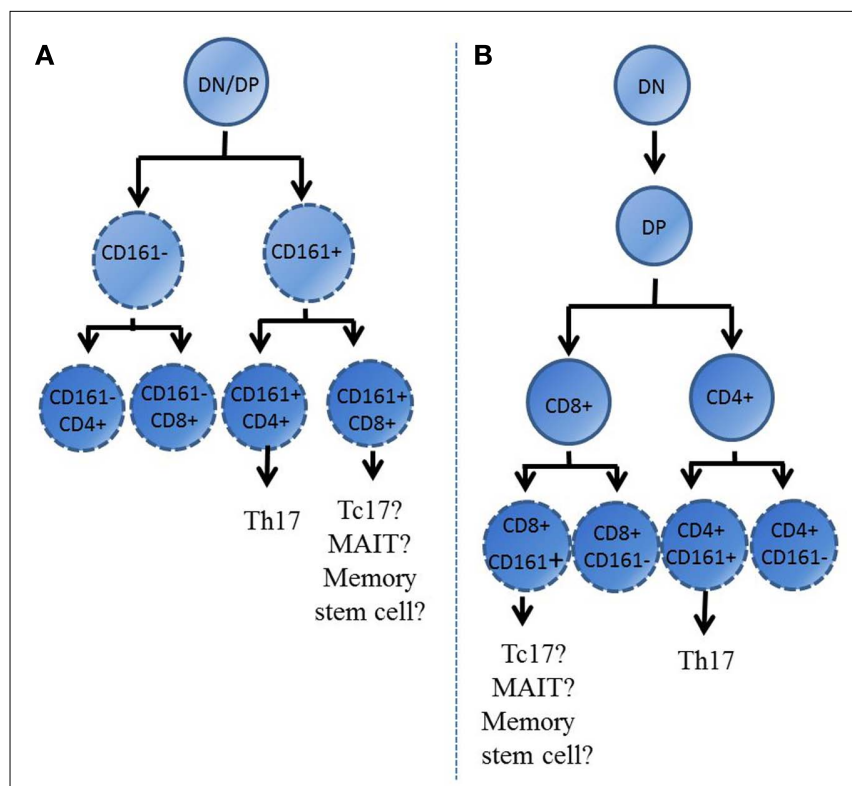

FIGURE 3 | Expression of CD161 early during the development of T cells within the thymus. This figure illustrates two possible pathways by which CD161 expression may be determined during development; either before co-receptor expression is decided $(\mathbf{A})$ or at the single positive stage, when T cells are either CD4+ or CD8+ (B). Th17 cells only develop from CD161+ CD4+ cells, however these cells can also develop into Th1 or Th2 cells. DN, double negative; DP, double positive. et al. (2009) of CD161 ${ }^{\text {high }}$ CD8 + T cells with stem cell-like properties. Expression of CD161 during development suggests that these cells may become precommitted to display characteristics of a "CD161 positive" phenotype, possessing shared characteristics independent of helper/cytotoxic lineage, such as IL-17 secretion. As such, this phenotypic commitment may be decided prior to further lineage development, as suggested in Figure 3A. Programmed chemokine receptor expression in CD161+ naïve cells, such as CCR6, may also indicate the ability of these cells to preferentially home to specific tissues, where they are found in elevated numbers (Huarte et al., 2008; Spreu et al., 2010). Evidently the development of CD161-expressing cells is still largely unexplored. However, clarification of the significance of CD161 expression during ontogeny may provide clues regarding the function of this unique cell type.

As CD161 marks $\mathrm{T}$ cells with the ability to secrete IL-17 (Maggi et al., 2010), expression of CD161 during development would appear to commit cells to a type 17 pathway of differentiation. However, CD161 expression was also identified on IFN $\gamma+$ and IFN- $\gamma /$ IL-17 co-secreting CD8+ (Billerbeck et al., 2010) and CD4+ T cells (Cosmi et al., 2008). CD4+IL-17+IFN $\gamma+$ cells have been termed Th17-1 (Jadidi-Niaragh and Mirshafiey, 2011) and express the chemokine receptors CCR6 and CXCR3, distinguishing them from Th17 cells which express CCR6 and CCR4 (AcostaRodriguez et al., 2007). However, whether these cells represent a stable subset or a transitional phenotype (El-behi et al., 2010) is yet to be resolved, with the latter case suggesting plasticity within the Th17 phenotype. Indeed, human Th17 clones have been shown to demonstrate a degree of plasticity when stimulated in the presence of IL-12, downregulating ROR $\gamma \mathrm{t}$ while upregulating the Th1 transcription factor T-bet, with these cells subsequently producing IFN- $\gamma$ in addition to IL-17 (Annunziato et al., 2007). Therefore, while CD161 is agreed to mark Th17 cells, and descriptions of these cells are extensive, the dual functionality demonstrated by some also reveals the difficulty in exclusively categorizing $\mathrm{T}$ cells into distinct subsets.

It is clear that much is left to be determined regarding the significance of CD161 expression, and further of different levels of expression, by this subset of human T cells. Studies to identify this receptor's ligands, and more importantly the effect of ligand binding on $\mathrm{T}$ cell function, will provide clues regarding the purpose of CD161 expression. In addition, characterization of both the phenotype and function of these subsets is fundamental to enabling their role within human diseases to be determined. The suggestion that CD161 supports activation-induced expansion of T cells (Huarte et al., 2008), and the implication of CD161 polymorphisms within MS (Hafler et al., 2007) could identify CD161, or indeed other receptors on CD161+ T cells, as potential therapeutic targets in the treatment of a wide range of diseases.

\section{ACKNOWLEDGMENTS}

We are grateful to Lucy Walker, Yu-Hoi Kang, Chris B. Willberg, and Kira Smith for work referred to in this article. Joannah R. Fergusson is funded by the Wellcome Trust, Vicki M. Fleming, and Paul Klenerman by Wellcome Trust (WT091663MA), MRC, NIHR Biomedical Research Centre, Oxford, the James Martin School for twenty first Century, Oxford, and the NIH NIAID 1U19AI082630-01. 


\section{REFERENCES}

Acosta-Rodriguez, E. V., Rivino, L., Geginat, J., Jarrossay, D., Gattorno, M., Lanzavecchia, A., Sallusto, F., and Napolitani, G. (2007). Surface phenotype and antigenic specificity of human interleukin 17-producing $\mathrm{T}$ helper memory cells. Nat. Immunol. 8, 639-646.

Aldemir, H., Pro'homme, V., Dumaurier, M., Retiere, C., Poupon, G., Cazareth, J., Bihl, F., and Braud, V. M. (2005). Cutting edge: lectinlike transcript 1 is a ligand for the CD161 receptor. J. Immunol. 175 , 7791-7795.

Annibali, V., Ristori, G., Angelini, D. F., Serafini, B., Mechelli, R., Cannoni, S., Romano, S., Paolillo, A., Abderrahim, H., Diamantini, A., Borsellino, G., Aloisi, F., Battistini, L., and Salvetti, M. (2011). CD161highCD8+T cells bear pathogenetic potential in multiple sclerosis. Brain 134, 542-554.

Annunziato, F., Cosmi, L., Santarlasci, V., Maggi, L., Liotta, F., Mazzinghi, B., Parente, E., Filí, L., Ferri, S., Frosali, F., Giudici, F., Romagnani, P., Parronchi, P., Tonelli, F., Maggi, E., and Romagnani, R. (2007). Phenotypic and functional features of human Th17 cells. J. Exp. Med. 204, 1849-1861.

Aust, J. G., Gays, F., Mickiewicz, K. M., Buchanan, E., and Brooks, C. G. (2009). The expression and function of the NKRP1 receptor family in C57BL/6 mice. J. Immunol. 183, 106-111.

Bezouska, K., Yuen, C. T., O’Brien, J., Childs, R. A., Chai, W., Lawson, A. M., Drbal, K., Fiserová, A., Pospísil, M., and Feizi, T. (1994). Oligosaccharide ligands for NKR-P1 protein activate NK cells and cytotoxicity. Nature 372, 150-157.

Billerbeck, E., Kang, Y., Walker, L., Lockstone, H., Grafmueller, S., Fleming, V., Flint, J., Willberg, C. B., Bengsch, B., Seigel, B., Ramamurthy, N., Zitzmann, N., Barnes, E. J., Thevanayagam, J., Bhagwanani, A., Leslie, A., Oo, Y. H., Kollnberger, S., Bowness, P., Drognitz, O., Adams, D. H., Blum, H. E., Thimme, R., and Klenerman, P. (2010). Analysis of CD161 expression on human CD8+ $\mathrm{T}$ cells defines a distinct functional subset with tissue-homing properties. Proc. Natl. Acad. Sci. U.S.A. 107, 3006-3011.

Carlyle, J. R., Jamieson, A. M., Gasser, S., Clingan, C. S., Arase, H., and Raulet, D. H. (2004). Missing self-recognition of Ocil/Clr-b by inhibitory NKR-P1 natural killer cell receptors. Proc. Natl. Acad. Sci. U.S.A. 101, 3527-3532.

Carlyle, J. R., Mesci, A., Ljutic, B. Belanger, S., Tai, L. H., Rousselle, E., Troke, A. D., Proteau, M. F., and Makrigiannis, A. P. (2006). Molecular and genetic basis for straindependent NK1.1 alloreactivity of mouse NK cells. J. Immunol. 176, 7511-7524.

Cosmi, L., De Palma, R., Santarlasci, V., Maggi, L., Capone, M., Frosali, F., Rodolico, G., Querci, V., Abbate, G., Angeli, R., Berrino, L., Fambrini, M., Caproni, M., Tonelli, F., Lazzeri, E., Parronchi, P., Liotta, F., Maggi, E., Romagnani, S., and Annunziato, F. (2008). Human interleukin 17-producing cells originate from a CD161+CD4+ $\mathrm{T}$ cell precursor. J. Exp. Med. 205 1903-1916.

Cua, D. J., Sherlock, J., Chen, Y., Murphy, C. A., Joyce, B., Seymour, B., Lucian, L., To, W., Kwan, S., Churakova, T., Zurawski, S., Wiekowski, M., Lira, S. A., Gorman, D., Kastelein, R. A., and Sedgwick, J. D. (2003). Interleukin23 rather than interleukin-12 is the critical cytokine for autoimmune inflammation of the brain. Nature 421, 744-748.

Dusseaux, M., Martin, E., Serriari, N. Peguillet, I., Premel, V., Louis, D., Milder, M., Le Bourhis, L., Soudais, C., Treiner, E., and Lantz, O. (2011). Human MAIT cells are xenobiotic resistant, tissue-targeted, CD161hi IL-17 secreting T cells. Blood 117, 1250-1259.

El-behi, M., Rostami, A., and Ciric, B. (2010). Current views on the roles of Th1 and Th17 cells in experimental autoimmune encephalomyelitis. J. Neuroimmune Pharmacol. 5 189-197.

Glimcher, L., Shen, F. W., Cantor, H. (1977). Identification of a cellsurface antigen selectively expressed on the natural killer cell. J. Exp. Med. 145, 1-9.

Gold, M. C., Cerri, S., Smyk-Pearson, S., Cansler, M. E., Vogt, T. M., Delepine, J., Winata, E., Swarbrick, G. M., Chua, W. J., Yu, Y. Y. L. Lantz, O., Cook, M. S., Null, M. D., Jacoby, D. B., Harriff, M. J., Lewinsohn, D. A., Hansen, T. H., and Lewinsohn, D. M. (2010). Human mucosal associated invariant $\mathrm{T}$ cells detect bacterially infected cells. PLoS Biol. 8, el000407. doi: $\quad 10.1371 /$ journal.pbio 1000407

Gumperz, J. E., Miyake, S., Yamamura, T., and Brenner, M. B. (2002). Functionally distinct subsets of CD1d- restricted natural killer $\mathrm{T}$ cells revealed by CD1d tetramer staining. J. Exp. Med. 195, 625-636.

Hafler, D. A., Compston, A., Sawcer, S., Lander, E. S., Daly, M. J., De Jager, P. L., de Bakker, P. I., Gabriel S. B., Mirel, D. B., Ivinson, A. J., Pericak-Vance, M. A., Gregory, S G., Rioux, J. D., McCauley, J. L. Haines, J. L., Barcellos, L. F., Cree, B., Oksenberg, J. R., and Hauser, S. L. (2007). Risk alleles for multiple sclerosis identified by a genomewide study. N. Engl. J. Med. 357, 851-862.

Hamada, H., Garcia-Hernandez, M. D. L. L., Reome, J. B., Misra, S. K., Strutt, T. M., McKinstry, K. K., Cooper, A. M., Swain, S. L., and Dutton, R. W. (2009). Tc17, a unique subset of CD8 $\mathrm{T}$ cells that can protect against lethal influenza challenge. J. Immunol. 182, 3469-3481.

Huarte, E., Cubillos-Ruiz, J. R., Nesbeth, Y. C., Scarlett, U. K., Martinez, D. G. Engle, X. A., Rigby, W. F., Pioli, P. A., Guyre, P. M., and Conejo-Garcia, J. R. (2008). PILAR is a novel modulator of human T-cell expansion. Blood 112, 1259-1268.

Huber, M., Heink, S., Grothe, H. Guralnik, A., Reinhard, K., Elflein, K., Hünig, T., Mittrücker, $\mathrm{H}$ W., Brüstle, A., Kamradt, T., and Lohoff, M. (2009). Th17-like developmental process leads to CD8+ Tc17 cells with reduced cytotoxic activity. Eur. J. Immunol. 39, 1716-1725.

Iizuka, K., Naidenko, O. V., Plougastel, B. F., Fremont, D. H., and Yokoyama, W. M. (2003). Genetically linked C-type lectin-related ligands for the NKRP1 family of natural killer cell receptors. Nat. Immunol. 4, 801-807.

Ishihara, S., Nieda, M., Kitayama, J., Osada, T., Yabe, T., Ishikawa, Y., Nagawa, H., Muto, T., and Juji, T. (1999). CD8+NKR-P1A+ $\mathrm{T}$ cells preferentially accumulate in human liver. Eur. J. Immunol. 29 2406-2413

Ivanov, I. I., McKenzie, B. S., Zhou, L. Tadokoro, C. E., Lepelley, A., Lafaille, J. J., and Cua, D. J., and Littman, D. R. (2006). The orphan nuclear receptor ROR $\gamma$ t directs the differentiation program of proinflammatory IL-17+ T helper cells. Cell 126 1121-1133.

Jadidi-Niaragh, F., and Mirshafiey, A (2011). Th17 cell, the new player of neuroinflammatory process in multiple sclerosis. Scand. J. Immunol. 74 1-13.

Kleinschek, M. A., Boniface, K., Sadekova, S., Grein, J., Murphy, E. E., Turner, S. P., Raskin, L., Desai, B.,
Faubion, W. A., de Waal Malefyt, R., Pierce, R. H., McClanahan, T., and Kastelein, R. A. (2009). Circulating and gut-resident human Th17 cells express CD161 and promote intestinal inflammation. J. Exp. Med. 206, 525-534.

Kondo, T., Takata, H., Matsuki, F., and Takiguchi, M. (2009). Cutting edge: Phenotypic characterization and differentiation of human CD8+ $\mathrm{T}$ cells producing IL-17. J. Immunol. 182, 1794-1798.

Koo, G. C., and Peppard, J. R. (1984) Establishment of monoclonal antiNk-1.1 antibody. Hybridoma 3, 301-303.

Lanier, L., Chang, C., and Phillips, J. (1994). Human NKR-P1A. A disulfide-linked homodimer of the C-type lectin superfamily expressed by a subset of $\mathrm{NK}$ and $\mathrm{T}$ lymphocytes. J. Immunol. 153, 2417-2428.

Le Bourhis, L., Martin, E., Péguillet, I., Guihot, A., Froux, N., Coré, M., Lévy, E., Dusseaux, M., Meyssonnier, V., Premel, V., Ngo, C., Riteau, B., Duban, L., Robert, D., Rottman, M., Soudais, C., and Lantz, O. (2010). Antimicrobial activity of mucosalassociated invariant $\mathrm{T}$ cells. Nat Immunol. 11, 701-708.

Lock, C., Hermans, G., Pedotti, R., Brendolan, A., Schadt, E., Garren, H. Langer-Gould, A., Strober, S., Cannella, B., Allard, J., Klonowski, P., Austin, A., Lad, N., Kaminski, N., Galli, S. J., Oksenberg, J. R., Raine, C. S., Heller, R., and Steinman, L. (2002). Gene-microarray analysis of multiple sclerosis lesions yields new targets validated in autoimmune encephalomyelitis. Nat. Med. 8, 500-508.

MacDonald, H. R. (1995). NK1.1+ $\mathrm{T}$ cell receptor-alpha/beta+ cells: new clues to their origin, specificity, and function. J. Exp. Med. 182, 633-638.

Maggi, L., Santarlasci, V., Capone1, M. Peired, A., Frosali, F., Crome, S., Querci, V., Fambrini, M., Liotta, F., Levings, M., Maggi, E., Cosmi, L., Romagnani, S., and Annunziato, F (2010). CD161 is a marker of all human IL-17-producing T-cell subsets and is induced by RORC. Eur. J. Immunol. 40, 2174-2181.

Martin, E., Treiner, E., Duban, L. Guerri, L., Laude, H., Toly, C., Premel, V., Devys, A., Moura, I. C., Tilloy, F., Cherif, S., Vera, G., Latour, S., Soudais, C., and Lantz, O. (2009). Stepwise development of MAIT cells in mouse and human. PLoS Biol. 7, e54. doi: 10.1371/journal.pbio. 1000054 
Northfield, J. W., Kasprowicz, V., Lucas, M., Kersting, N., Bengsch, B., Kim, A., Phillips, R. E., Walker, B. D., Thimme, R., Lauer, G., and Klenerman, P. (2008). CD161 expression on hepatitis C virus-specific CD8+ $\mathrm{T}$ cells suggests a distinct pathway of $\mathrm{T}$ cell differentiation. Hepatology 47, 396-406.

O'Keeffe, J., Doherty, D., Kenna, T., Sheahan, K., O’Donoghue, D., Hyland, J., and O'Farrelly, C. (2004). Diverse populations of $\mathrm{T}$ cells with NK cell receptors accumulate in the human intestine in health and in colorectal cancer. Eur. J. Immunol. 34, 2110-2119.

Plougastel, B., Matsumoto, K., Dubbelde, C., and Yokoyama, W. M. (2001a). Analysis of a 1-Mb BAC contig overlapping the mouse Nkrp1 cluster of genes: cloning of three new Nkrpl members, Nkrpld, Nkrple, and Nkrplf. Immunogenetics 53, 592-598.

Plougastel, B. F., Dubbelde, C., and Yokoyama, W. M. (2001b). Cloning of Clr, a new family of lectinlike genes localized between mouse Nkrpla and Cd69. Immunogenetics 53, 209-214.

Poggi, A., Costa, P., Zocchi, M. R., and Moretta, L. (1997).
NKRP1A molecule is involved in transendothelial migration of CD4+ human $\mathrm{T}$ lymphocytes. Immunol. Lett. 57, 121-123.

Rosen, D. B., Bettadapura, J., Alsharifi, M., Mathew, P. A., Warren, H. S., and Lanier, L. L. (2005). Cutting edge: lectin-like transcript- 1 is a ligand for the inhibitory human NKR-P1A receptor. J. Immunol. 175, 7796-7799.

Rosen, D. B., Cao, W., Avery, D. T., Tangye, S. G., Liu, Y., Houchins, J. P., and Lanier, L. L. (2008). Functional consequences of interactions between human NKR-P1A and its ligand LLT1 expressed on activated dendritic cells and B cells. $J$. Immunol. 180, 6508-6517.

Rowan, A. G., Fletcher, J. M., Ryan, E. J., Moran, B., Hegarty, J. E., O'Farrelly, C., and Mills, K. H. (2008). Hepatitis $\mathrm{C}$ virus-specific Th17 cells are suppressed by virus-induced TGF- $\beta$. $J$. Immunol. 181, 4485-4494.

Spreu, J., Kuttruff, S., Stejfova, V., Dennehy, K. M., Schittek, B., and Steinle, A. (2010). Interaction of Ctype lectin-like receptors NKp65 and KACL facilitates dedicated immune recognition of human keratinocytes. Proc. Natl. Acad. Sci. U.S.A. 107, 5100-5105.
Takahashi, T., Dejbakhsh-Jones, S., and Strober, S. (2006). Expression of CD161 (NKR-P1A) defines subsets of human CD4 and CD8 T cells with different functional activities. $J$. Immunol. 176, 211-216.

Turtle, C. J., Swanson, H. M., Fujii, N., Estey, E. H., and Riddell, S. R. (2009). A distinct subset of self-renewing human memory CD8+ $\mathrm{T}$ cells survives cytotoxic chemotherapy. Immunity 31 , 834-844.

Tzartos, J. S., Friese, M. A., Craner, M. J., Palace, J., Newcombe, J., Esiri, M. M., and Fugger, L. (2008). Interleukin17 production in central nervous system-infiltrating $\mathrm{T}$ cells and glial cells is associated with active disease in multiple sclerosis. Am. J. Pathol. 172, 146-155.

Walker, L., Kang, Y., Smith, M., Oo, Y., Barnes, E., Lauer, G., Adams, D. H., and Klenerman, P. (2010). P74 CD161 expressing CD8+ T-cells; elusive players in viral hepatitis. Gut 59(Suppl. 2), A100.

Wang, L., Chen, S., Xu, K. (2011). IL-17 expression is correlated with hepatitis B-related liver diseases and fibrosis. Int. J. Mol. Med. 27, 385-392.

Zenewicz, L. A., Yancopoulos, G. D., Valenzuela, D. M., Murphy,
A. J., Karow, M., and Flavell, R. A. (2007). Interleukin-22 but not interleukin-17 provides protection to hepatocytes during acute liver inflammation. Immunity 27 , 647-659.

Conflict of Interest Statement: The authors declare that the research was conducted in the absence of any commercial or financial relationships that could be construed as a potential conflict of interest.

Received: 07 May 2011; accepted: 11 August 2011; published online: 30 August 2011.

Citation: Fergusson JR, Fleming VM and Klenerman P (2011) CD161-expressing human T cells. Front. Immun. 2:36. doi: 10.3389/fimmu.2011.00036

This article was submitted to Frontiers in Immunological Memory, a specialty of Frontiers in Immunology.

Copyright (c) 2011 Fergusson, Fleming and Klenerman. This is an open-access article subject to a non-exclusive license between the authors and Frontiers Media $S A$, which permits use, distribution and reproduction in other forums, provided the original authors and source are credited and other Frontiers conditions are complied with. 